\title{
Enteral feeding pumps: efficacy, safety, and patient acceptability
}

This article was published in the following Dove Press journal:

Medical Devices: Evidence and Research

19 August 2014

Number of times this article has been viewed

\section{Helen White \\ Linsey King}

Nutrition and Dietetic Group, School of Health and Wellbeing, Faculty Health and Social Science, Leeds Metropolitan University, Leeds, United Kingdom
Correspondence: Helen White Nutrition and Dietetic Group (Broadcasting Place 207), School of Health and Wellbeing, Faculty Health and Social Science, Leeds Metropolitan University, Calverley Street, Leeds LSI 3HE, United Kingdom Email h.white@leedsmet.ac.uk

\begin{abstract}
Enteral feeding is a long established practice across pediatric and adult populations, to enhance nutritional intake and prevent malnutrition. Despite recognition of the importance of nutrition within the modern health agenda, evaluation of the efficacy of how such feeds are delivered is more limited. The accuracy, safety, and consistency with which enteral feed pump systems dispense nutritional formulae are important determinants of their use and acceptability. Enteral feed pump safety has received increased interest in recent years as enteral pumps are used across hospital and home settings. Four areas of enteral feed pump safety have emerged: the consistent and accurate delivery of formula; the minimization of errors associated with tube misconnection; the impact of continuous feed delivery itself (via an enteral feed pump); and the chemical composition of the casing used in enteral feed pump manufacture. The daily use of pumps in delivery of enteral feeds in a home setting predominantly falls to the hands of parents and caregivers. Their understanding of the use and function of their pump is necessary to ensure appropriate, safe, and accurate delivery of enteral nutrition; their experience with this is important in informing clinicians and manufacturers of the emerging needs and requirements of this diverse patient population. The review highlights current practice and areas of concern and establishes our current knowledge in this field.
\end{abstract}

Keywords: nutrition, perceptions, experience

\section{Introduction}

Enteral tube feeding has been in place for 3,500 years. Originally used by the ancient Greeks and Egyptians, its early aims were to alleviate various bowel disorders through infusion of nutrient solutions into the rectum. In the 16th century, the use of hollow tubes with attached animal bladders enabled esophageal feeding, and the first recorded provision of feeding into the upper gastrointestinal tract. ${ }^{1}$ These devices were later supplanted by leather tubes and whale bones covered with eel skins and then by rubber tubes. ${ }^{2}$

Since these early reports, enteral tube feeding has evolved to encompass modern nasogastric feeding using fine polyethylene tubes, ${ }^{3}$ nasojejunal tubes, and percutaneous endoscopic gastrostomy and radiologically inserted gastrostomy techniques. ${ }^{4-6}$ These improvements, alongside the development of wide ranges of nutritional formulae and enteral feed pump systems have ensured that enteral nutrition is an effective intervention across disease spectrums. Enteral feeding can contribute to improved outcomes for those with long-term chronic disease conditions ${ }^{7,8}$ and can benefit those with marked disease complexity and severity. ${ }^{9}$ The composition, timing, and mode of delivery also continue to be evaluated across health conditions to better understand the clinical impact of enteral feeding itself. ${ }^{10-12}$ 
Despite a recognition of the importance of enteral nutrition, ${ }^{13-15}$ evaluation of the efficacy of formula delivery is more limited. The accuracy, safety, and consistency with which the formula is delivered are important determinants of the use and acceptability of enteral feeding pump systems. These principles are important to patients and health care providers alike and are necessary to ensure confidence and acceptance of enteral tube feeding at a time when patients can feel at their most vulnerable.

Manufacturers of enteral feed pump devices have, in turn, responded to clinician and service user requirements, and pump therapy is now the chosen mode of delivery across a range of conditions and settings. This review establishes our knowledge to date regarding the efficacy and safety of enteral feeding pumps and our understanding of patient experiences and requirements within current health care practice.

\section{Enteral feed pump systems and efficacy}

The first enteral feed pump was reportedly used by an Englishman named Reeve in the 19th Century ${ }^{16}$ but became more widely known as a means of enteral feed delivery following the development and introduction of a feeding pump by Edward Barron in 1956. A unique collaboration between medical and engineering staff based at the Henry Ford Hospital and the Chrysler Corporation resulted in the development of a "food pump", which delivered pureed food through a small nasogastric tube. ${ }^{17}$ It was recognized that to aid tolerance, a slow and constant feeding rate was required in elderly and critically ill patients and those requiring duodenal and jejunal feeding. A feeding pump was considered a better vehicle than gravity-driven bolus feeds or the continuous infusion of enteral feeding regulated by a roller clamp attached to the tubing.

Despite this recognition, enteral feed pumps were only used more widely from the 1970s onwards, coinciding with the development of nutritional formulae..$^{18}$ Rotary and linear peristaltic mechanisms in which fluid was alternately compressed and decompressed against rollers, or an opposing surface, preceded the use of volumetric mechanisms, which improved accuracy further through compression of a preset amount of fluid into a cassette before controlled delivery into the infusion tubing. ${ }^{19,20}$ By the late 1990s enteral feeding pump systems had developed additional safety features, including microprocessor controls, screen displays for programming options, improved identification of alarm conditions, automatic tube flush, anti-free-flow protection, a delivery set security door, and safeguards against overinfusion..$^{21,22}$
Alongside these advances, ambulatory pumps addressed the greater mobility needs of patients on longer-term enteral tube feeding. The introduction of cassettes that prevented inadvertent flow errors and triggering of alarm processes addressed the limitations of volumetric pump systems that had required upright positioning to avoid persistent alarming, ${ }^{23}$ and contributed to improved quality of life. ${ }^{24}$ These devices are now the norm. ${ }^{25-29}$ Whilst national guidance documentation has continued to advocate gravity feeding as the first-line delivery of enteral feeding in some countries, ${ }^{14,15}$ the use of enteral feed pumps is now considered the most accurate means of enteral feeding provision across all care settings and patient groups. Systems have become increasingly robust. Operating temperatures range from $10^{\circ} \mathrm{C}$ to $40^{\circ} \mathrm{C}^{27}$ and storage temperatures from $-13^{\circ} \mathrm{C}$ to $45^{\circ} \mathrm{C},,^{25}$ allowing functionality across a wide range of environments. Pumps continue to employ microprocessors that enable the delivery of controlled enteral feeding..$^{27}$ Automatic priming, dose setting, advanced memory, and the continuing use of easily loaded cassettes, for one-handed consistent pump setup, are now integral features. Flow rate selection offers incremental increases in delivery; important in critical care settings where low infusion rates are crucial in maintaining gut integrity and where tolerance and maximizing the feeding volume are finely balanced. Flow rate selection ranging from $1-300 \mathrm{~mL}$ in $1 \mathrm{~mL}$ increments and accuracy to within $\pm 10 \%$ (with pediatric and some adult systems adhering to deviance rates of only $\pm 5 \%$ ) are therefore integral to modern pump systems. ${ }^{25,27}$ Some pumps advertise selectable flow rates ranging from $0.1 \mathrm{~mL} /$ hour to $600 \mathrm{~mL} /$ hour, alongside bolus, and continuous and intermittent feed programs, and a 24-hour battery, demonstrating the level of accuracy and features required in current markets..$^{29,30}$

Value and cost effectiveness have remained important throughout, although economic evaluation has focused mainly on the clinical outcomes ${ }^{31}$ and quality-adjusted life years ${ }^{32}$ associated with enteral tube feeding rather than the actual cost of enteral pump-assisted delivery per se. Economic evaluation of use of enteral feeding is limited and has been restricted to the financial benefits ${ }^{33}$ and nursing costs associated with pump systems that employ an open or closed system of delivery. ${ }^{34}$ The argument has centered on whether open systems, which allow the decanting of precise volumes of feed and potentially less wastage, can overcome the nursing cost of more frequent 4- to 6-hourly changes of container and the potential for reduced microbial safety. In contrast, the preset feeding volumes of closed systems may result in feed wastage but have the advantage of 24-hour hanging times, 
greater microbial safety, and less nursing input. Overall, it has been shown that closed systems are more cost effective, when the nursing time associated with administration of an open system is accounted for. ${ }^{34}$

\section{Enteral feed pump safety}

With the increased prevalence of enteral nutrition use across the hospital and home sector, interest in safe delivery and provision has also risen. Ensuring the safety of enteral feed pump sets is important to enteral pump manufacturers but also for patients themselves. Although limited published data exists that has evaluated aspects of enteral pump safety, four areas have emerged: the consistent and accurate delivery of the formula; the minimization of errors associated with tube misconnection; the impact of continuous feed delivery (via an enteral feed pump); and risks related to the chemical composition of the casing used in enteral feed pump manufacture.

\section{Accuracy of enteral feed pumps}

Where accuracy is paramount, the failure of enteral feed pumps to deliver prescribed volumes can present a risk for safe feeding practice. The accuracy of enteral pump sets is crucial within critical care settings and for specific patient groups, such as neonates, where minimal differences between prescribed and actual intakes in fluid can have significant consequences. An inadequate delivery of enteral nutrition and a low rate of nutrition prescription in critical care settings have been well documented; in many instances due to underprescription, feeding interruption, and nursing and medical practice. ${ }^{35-38} \mathrm{~A}$ number of studies have also established that inaccuracy in enteral pump function plays a role in delivery. ${ }^{36,39,40,41}$ Dietscher et al tested, in five replications, the use of three brands of enteral feed pump with differing nutritional formulae. ${ }^{39}$ The percentage of expected flow rate was calculated for each in vitro. The study concluded that a highly viscous formula $(2 \mathrm{kcal} / \mathrm{mL})$ that also had additional powdered nutrient modules added to further enhance calorie content provided the lowest percentage flow rates of all formulae and for one combination of feed and enteral pump set, was as low as $53 \%$. Although there were dramatic differences, the study had a number of limitations that should be acknowledged. The flow rates were assessed in vitro and did not necessarily mirror in vivo enteral feed infusion, where the positioning of the nasogastric tube itself and of the patient's body position may both influence flow rates. The high infusion rates of 300 $\mathrm{mL} /$ hour that the study reported also reflect much higher infusion rates than is normal practice, as does the addition of modular powders to a high viscosity feed formula.
As differences in accuracy could be attributed to the different viscosities of enteral tube formulae and to bending or twisting of the tubing as a patient moves, it was proposed that deviations should be evaluated fully by measuring within different settings, between varying formulae, and under differing conditions. ${ }^{16,36}$

Findings were therefore tested further by Tepaske et al, who investigated 13 commercially available enteral nutrition (EN) pump systems within a laboratory setting, to evaluate their accuracy. ${ }^{40}$ Accuracy was defined as the difference between a preset volume and the actually delivered volume (in vitro), over a 24-hour uninterrupted period. On this occasion, only a single pump of each type was used, although reproducibility was checked for each. All of the enteral nutrition pumps revealed deficits in enteral feed delivery ranging from a minimal deficit of $0.5 \%$ through to $13.5 \%$. A lack of correlation between the accuracy of the EN pump and the resistance in the feeding tubes suggested that, in part, the reduced accuracy was attributable to the EN pump feeding systems and not to the viscosity of the enteral feeding formula. Although the authors accepted the limitations of the testing of only a single pump from each manufacturer, and therefore the assumption that each pump would be representative of all pumps of the same type, their findings were corroborated by a second study which confirmed the structural underdelivery of formula, when 6-8 pumps of the same type were tested for two enteral nutrition pump systems over a 1-hour period. ${ }^{41}$ Certain pumps demonstrated heightened discrepancies despite frequent technical service recalibration, suggesting that calculated nutrition requirements could not be assured for all patients. A third study reiterated these findings and suggested that frequent recalibration of enteral pump settings, particularly when used in critical settings, should be the norm. ${ }^{36}$ This becomes even more imperative for pediatric enteral feed pumps, where accuracy must lie within a more stringent margin, of $\pm 5 \%$ of set volume - greater deviations than this in pediatric and infant pumps has greater impact for an infant. The American Society of Enteral and Parenteral Nutrition has emphasized that deficits of $10 \%$ may compromise brain growth and crucial developmental targets. ${ }^{14}$ In response, manufacturers have continued to improve the accuracy and reduce the setting increments for pump flow rates so that there is maximal flexibility in delivering very small volumes of feed, with some pumps now delivering volumes of 0.1 to $600 \mathrm{~mL}$ in $1 \mathrm{~mL}$ increment settings. ${ }^{30}$

\section{Enteral feed pump misconnections}

Although an enteral feed misconnection was first reported in 1972, indicating that breast milk had erroneously been 
delivered into an intravenous rather than enteral feed line, ${ }^{42}$ this patient safety issue received little attention until American and UK national patient safety alerts were issued in 2006 and 2007, through the Joint Commission Sentinel Event Alert ${ }^{43}$ and the National Patient Safety Agency (NPSA) National Patient Alert. ${ }^{44}$ Multiple connections between medical devices and tubing have been common in patient care. Luer connectors are ubiquitous, easy-to-use, and historically have been compatible between systems, thus causing medication and enteral feed delivery errors by administration through the wrong route.

In 2005-2006, the NPSA responded to 33 documented safety incidents involving oral liquids given via the parenteral rather than enteral route. ${ }^{44} \mathrm{~A}$ similar report in an American population identified 24 incidents where enteral feed formula, solutions, or medication intended for an enteral feeding tube were administered via an incorrect route in 2000-2006, of which $33 \%$ had resulted in sentinel events of permanent injury, life threatening situations, or death. ${ }^{45}$ Specific patient groups are considered at particularly high risk, including neonates, in whom enteral feeding has often involved small infusion volumes, which in turn, has encouraged use of intravenous syringes alongside enteral feed equipment to deliver these smaller doses. ${ }^{46}$

The multifactorial approach to resolving incidents has incorporated a "whole systems" approach to addressing the principal causes of error. Recommended solutions have addressed education, awareness, human factors, purchasing strategies, and design changes. ${ }^{45}$ The Joint Commission urged the medical device industry to implement appropriate "incompatibility by design" strategies to prevent misconnection, proposing redesign of connectors to make incorrect connection impossible, widely accepted as the most effective tool to prevent inadvertent error. ${ }^{47-49}$

Despite the design of novel adaptors, nonstandard connectors, the use of "purple" color coding for enteral feed systems, improved labeling of enteral feeding devices, and directives that advise against additional connectors within systems, to further minimize risk, mistakes have continued to occur. This highlights the role of human error and emphasizes that visual cues alone are insufficient to overcome human error. Without a defined standard for connectors, manufacturers will remain challenged to create products that interface with parts they do not manufacture themselves. To address this issue, in 2012, the United States Food and Drug Administration (FDA) commissioned manufacturers to collaborate in devising international standards for enteral connections. ${ }^{50}$ The International Organization for Standardization (ISO) is expected to publish agreed standards in 2014 that will offer manufacturers information on how to create proprietary connectors for their enteral feeding devices.

\section{Safety mechanisms and enteral feed pump systems}

Whilst many of the above issues are a feature of the enteral feed "system" rather than the pump set itself, redesign of enteral pumps has also added additional safety features over time. Manufacturers have sought to reduce the critical incidents and sentinel events associated with pump error and inaccuracy, through the use of closed system pump sets that minimize tube disconnection and enhance microbiological safety. Incorporation of anti-free-flow devices into pump mechanisms has added further protection against the possibility of free-flow incidents, enabling patients to be confident that large volumes of feed cannot enter the gut as a single bolus. ${ }^{25-30}$ Use of continuous pump feeding is theoretically a safer means of formula delivery, through its potential to reduce high residual volumes and the risk of gastric aspiration. However, trials in trauma patients have not indicated this, ${ }^{51}$ and although early studies in frail elderly patients suggested that continuous pump feeding was advantageous, ${ }^{49}$ subsequent trials have failed to show reductions in aspiration pneumonia or gastric aspiration for those receiving continuous gastric feeding. ${ }^{52-54}$ In contrast, established benefits have been shown for continuous intrajejunal pump feeding to prevent aspiration in critically ill patients, where gastroparesis is common. ${ }^{55,56}$ The jejunum secretes fluid in response to hyperosmolar solutions, and too rapid delivery of a hyperosmolar nutrition formula results in abdominal distention, hyperperistalsis, and diarrhea. The rationale is that continuous pump infusions can help to prevent these symptoms through a more controlled delivery to the intestine.

\section{Enteral feed pump casing composition}

The composition of enteral feed pump casing itself has invited concern in recent years. Di-ethylhexyl phthalate (DEHP) is a compound whose function is to act as a plasticizer in medical devices and has been a component of feeding tubes and enteral pump devices in the past. In 2001 the FDA assessed the safety of DEHP in medical devices and concluded that specific devices exceeded the Agency's guidance for tolerable upper limits. ${ }^{57}$ This applied to all devices used for enteral nutrition. The US National Toxicology Program deemed that DEHP was a reproductive and developmental toxicant, 
having the potential to cause cellular abnormality through impairment of the Sertoli cells of the testes, in addition to affecting the structure and function of the male reproductive system. ${ }^{58}$ In animal studies, DEHP has also been shown to cause a particular risk to vulnerable populations, namely critically ill infants, healthy infants and toddlers, and pregnant women ${ }^{59}$ Whilst DEHP has primarily been added to polyvinyl chloride (PVC) feeding tubes in order to improve the flexibility of the tube, it has caused manufacturers to examine DEHP levels across all types of equipment, to ensure safety of all aspects of the enteral feeding process. To this extent, the manufacturers have promoted DEHP-free EN pump sets in a bid to market their safety.

\section{Patient perceptions of use of enteral feeding pumps}

The accuracy and safety of feeding pumps are, however, only a part of enteral pump system evaluation. Assessment of pump functionality is also required from patients and their caregivers as their feedback regarding the strengths and limitations of enteral pump devices is essential in ensuring appropriate, safe, and accurate delivery of enteral nutrition. Studies of patient and caregiver expectations and experiences of enteral feed pumps have been rare. Studies have focused on all aspects of enteral feeding and the life changes surrounding the long-term delivery of nutrition via an enteral feeding system, rather than considering the impact and issues of the use of pumps within the home environment. ${ }^{60-63}$

Of the limited accounts gathered from patients, their concerns have centered on the impact of incorrect equipment delivery, the longer-term issues of tube blockage, and the sleep disturbances related to activation of pump alarms for an unknown reason. ${ }^{64}$ The studies that have captured the experiences of caregivers and parents have explored their concerns regarding faulty or damaged pumps and the changes that have ensued after moving to a different enteral feeding pump company provider, rather than their preferences or views on enteral feeding pumps themselves. Thus, pump accuracy and delivery, ease of pump use, and personal requirements have not been considered fully. ${ }^{63}$ For this reason, recommendations arising from these studies have focused on the strategic development of appropriate local and regional agreements, in order to improve the accuracy, efficacy, and safety of enteral feed systems as a whole, and have lacked detail, gathered from service users' perspectives, regarding ideal pump requirements and the practicalities of using enteral feed pumps within daily life.
Those papers reflecting experience of home enteral feeding (HEF) have been mainly qualitative in design and have explored the experiences of consent, decision making, adjustment to home life after hospitalization, and perceptions of HEF. ${ }^{60-62}$ Participants reflected on the impact of HEF related to the difficulties and disruption it caused to everyday life and described their feelings of vulnerability. Although by design, sample sizes were small and limited to feedback of patients from a restricted geographical area, these studies give insight into the emotional issues of those involved in the life-changing event of HEF. Caregivers and health professionals were noted to have a poor understanding of each other's perceptions of enteral tube feeding, demonstrating a limited appreciation of each other's priorities and experience. Improved communication by health care professionals was needed at all stages of the home enteral feeding process, particularly to identify the information needs of caregivers, who believed they required more guidance for decision making. ${ }^{62}$ However, these decisions were concerned, not with the enteral feed pump itself but rather, with the timing of gastrostomy insertion.

Further studies have sought parents' and caregivers' views of enteral nutrition. Evans et al examined caregiver and parental views of the practicalities of HEF, in a sample of 82 children, reporting a number of practice safety issues. ${ }^{63}$ Within the study, $47 \%$ reported a delay in the first delivery of equipment, $41 \%$ had incorrect equipment delivered, $17 \%$ had difficulties in obtaining a feed prescription, and 24\% reported inadequate training following a postdischarge change in enteral feeding pump. The study highlighted the most important areas for manufacturers to consider and the detail and clarity required for enteral feeding contracting in ensuring adequate provision.

In a second study, Evans et al focused on overnight enteral feeding in children with metabolic disorders who required a high degree of pump accuracy and consistency to avoid destabilization of blood biochemical indices overnight. ${ }^{64}$ A significant number of safety issues were highlighted. In $73 \%$ of children, pump alarms were triggered, due primarily to feeding line occlusion; $32 \%$ reported faulty equipment due to leaking bags or kinked feeding lines that triggered the pump alarm system; and 29\% of children had disconnected themselves at least once from the pump feeding system. Importantly, $50 \%$ had experienced pump faults, at least once yearly, that affected feed accuracy and in one critical incident of underfeeding, had resulted in hypoglycemia and hospital admission. This illustrated the breadth and frequency of pump-associated incidents that occurred within this cohort 
and the difficulties to be overcome, although it gave no indication of child or parental views of enteral feeding pumps, which is so important in further informing safe, childproof, lightweight and portable enteral pump design.

In response to the need for children to be more mobile and to minimize restrictive routines, the development of lighter ambulatory pumps has become the norm, a change directly influenced by service users themselves. Portable feeding improves mobility, where previously this was restricted, and better enables those who receive enteral nutrition to face the challenges of everyday life. Ambulatory pumps offer an option for return to normality, particularly for children. ${ }^{65,66}$ In support of the need for portable equipment, Evans et al provided current context, indicating that $82 \%$ of the study subjects were mobile, and $90 \%$ had ambulatory pumps in backpacks. ${ }^{64}$ Changing trends in the age distribution of children on enteral tube feeds are also apparent. Within the UK, $69 \%$ of the 1,784 children registered as receiving enteral tube feeding are now less than 2 years old, and $80 \%$ are 5 years or under. ${ }^{63}$ Adult statistics have also risen, with 3,430 registered within the UK; of this number, those considered fully active rose from $17 \%$ in 2000 to $40 \%$ in $2010,{ }^{67}$ with corresponding requirements for aesthetic, user-friendly, and ambulatory pump devices that aid their independence.

The changing face of enteral feeding therefore endorses a more transparent and collaborative approach between manufacturers and service users, which has not yet been fully established. Where support for pump-related queries and incidents is lacking, web-based fora allow discussion of experiences and problems with pumps and feeding at home, and pump user acceptability. They demonstrate the practical issues of daily use and home enteral nutrition, ${ }^{68,69}$ and emphasize the alternative support approaches for service users that might be considered by clinicians and manufacturers in the future.

\section{Summary and conclusion}

Enteral feeding has advanced significantly since its conception. The use of enteral feeding pumps is now a standards-driven process for patients who require assistance with meeting nutritional requirements, when the oral route is ineffective. The safety of pumps has evolved with the advent of new closed systems that reduce incorrect administration and microbial risk and the development of feeding pumps that are user friendly and more accurate in their delivery of enteral nutrition formulae. Research regarding efficacy, safety, and especially patient experience is still limited. The patient population themselves are an important resource for clinicians and manufacturers. Their understanding, perceptions, and views will be important in informing future enteral feed provision and the most acceptable pump delivery systems for an increasingly diverse population.

\section{Disclosure}

Helen White reports consultancy payment from Abbott Nutrition, although not in the field of enteral pump feeding. The authors report no other conflicts of interest in this work.

\section{References}

1. Chernoff R. An overview of tube feeding: from ancient times to the future. Nutr Clin Pract. 2006;21(4):408-410.

2. Ewald CA. A ready method of washing out the stomach. Irish Gazette. 1874:254-255.

3. Fallis LS, Barron J. Gastric and jejunal alimentation with fine polyethylene tubes. AMA Arch Surg. 1952;65(3):373-381.

4. Gauderer MW, Ponsky JL, Izant RJ. Gastrostomy without laparotomy: a percutaneous endoscopic technique. J Pediatr Surg. 1980;15(6): 872-875.

5. Poinsky JL, Aszodi A. Percutaneous endoscopic jejunostomy. Am J Gastroenterol. 1984;70:113-116.

6. Deveney KE. Endoscopic gastronomy and jejunostomy. In: Rombeau JL, Caldwell MD, editors. Clinical Nutrition: Enteral and Tube Feeding. 2nd ed. Philadelphia, PA: WB Saunders Co; 1990:217-228.

7. Pearce C, Duncan H. Enteral feeding. Nasogastric, nasojejunal, percutaneous endoscopic gastrostomy, or jejunostomy: its indications or limitations. Postgrad Med J. 2002;78(918):198-204.

8. Ockenga J, Grimpble R, Jonkers-Schuitema, et al; DGEM (German Society for Nutritional Medicine); ESPEN (European Society for Parenteral and Enteral Nutrition). ESPEN guidelines on enteral nutrition: wasting in HIV and other chronic infectious diseases. Clin Nutr. 2006;25(2):319-329.

9. Akkersdijk WL, Roukema JA, van der Werken C. Percutaneous endoscopic gastrostomy for patients with severe cerebral injury. Injury. 1998;29(1):11-14.

10. Gomes CA, Lustosa SA, Matos D, Andriolo RB, Waisberg DR, Waisberg J. Percutaneous endoscopic gastrostomy versus nasogastric tube feeding for adults with swallowing disturbances. Cochrane Database Syst Rev. 2010;11:CD008096.

11. Kreymann KG, Berger MM, Deutz NEP, et al. ESPEN guidelines on enteral nutrition: intensive care. Clin Nutr. 2006;25:210-223.

12. Lewis SJ, Egger M, Sylvester PA, Thomas S. Early enteral feeding versus "nil by mouth" after gastrointestinal surgery: systematic review and meta-analysis of controlled trials. BMJ. 2001;323(7316):773-776.

13. National Institute for Clinical Excellence (NICE). Nutrition Support for Adults. Oral Nutrition Support, Enteral Tube Feeding and Parenteral Nutrition. London: National Collaborating Centre for Acute Care; 2006. Available from: http://www.nice.org.uk/nicemedia/ live/10978/29981/29981.pdf. Accessed March 28, 2014.

14. Bankhead R, Boullata J, Brantley S, et al. Enteral nutrition administration. In: ASPEN enteral nutrition practice recommendations. JPEN J Parenter Enteral Nutr. 2009;33(2):149-158.

15. Dietitians Association of Australia. Enteral nutrition manual for adults in health care facilities. Dietitians Association of Australia; 2011. Available from: http://daa.asn.au/wp-content/uploads/2011/11/Enteralnutrition-manual-Oct-2011.pdf. Accessed July 4, 2014.

16. Gorman RC, Nance ML, Morris JB. Enteral feeding techniques. In: Torosian MH, editor. Nutrition for the Hospitalized Patient: Basic Science and Principles of Practice. New York, NY; Marcel Dekker Inc.; 1995:329-351.

17. Barron J, Prendergast JJ, Jocz MW. Food pump; new approach to tube feeding. J Am Med Assoc. 1956;161(7):621-622. 
18. Forlaw KL, Chernoff R, Guenter P. Enteral delivery systems. In: Rombeau JL, Caldwell MD, editors. Clinical Nutrition: Enteral and Tube Feeding. 2nd ed. Philadelphia, PA: WB Saunders Co; 1990:174-190.

19. Goff KL. The nuts and bolts of enteral infusion pumps. Medsurg Nurs. 1997;6(1):9-15; quiz 16

20. Nobel JJ. Enteral feeding pumps. Pediatr Emerg Care. 1996;12(2): 128-136.

21. Viall C. Enteral feeding technology. Nursing. 1994;24(8):32J-32K.

22. Jones SA, Guenter P. Automatic flush feeding pumps. Nursing. 1997; 27(2):56-58.

23. Companion ${ }^{\circledR}$ Enteral nutrition pump operating manual [package insert]. Columbus, OH: Ross Products Division of Abbott Laboratories; 2001. Available from: http://www.meql.com/Manuals/Ross-CompanionFeeding-Pump-User-Manual.pdf. Accessed June 27, 2014.

24. Flexifo ${ }^{\circledR}$ Companion ${ }^{\circledR}$ Enteral nutrition pump operating manual [package insert]. Columbus, OH: Ross Products Division of Abbott Laboratories; 1995. Available from: http://www.bristolhomeinfusion.com/images docs/Companion_Operating_Manual.pdf. Accessed June 27, 2014.

25. Applix Smart Enteral Feeding Pump. Instructions for use [operating instructions]. Hamburg: Fresenius Kabi AG; 2011. Available from: http://www.fresenius-kabi.com/files/4137-2_nu_Applix_Smart_GB_ V1.pdf. Accessed March 29, 2014.

26. Nutricia Flocare Pumps [homepage on the Internet]. Nutricia Flocare; 2014 [cited March 29, 2014]. Available from: http://www.nutriciaflocare.com/flocare_page.php?data=pumprange. Accessed June 17, 2014.

27. Abbott FreeGo ${ }^{\circledR}$ Pump [training manual]. Mt Wellington: Abbott Laboratories NZ Ltd; 2011. Available from: http://www.abbottnutrition. com.au/Portals/0/img/EQP 004-0812-2ANZ_FreeGo Training_Abbott_ LR.pdf. Accessed March 29, 2014.

28. nestlehealthscience.us [homepage on the Internet]. Products: EnteralLite ${ }^{\circledR}$ Infinity ${ }^{\circledR}$ enteral feeding pump. Nestlé Healthcare Nutrition, Inc.; 2013 [cited March 29, 2014]. Available from: http:// www.nestlehealthscience.us/infinitypump. Accessed May 24, 2014.

29. Kangaroo ${ }^{\mathrm{TM}}$ Joey enteral feed and flush pump with pole clamp, programmable [product brochure]. Mansfield, MA: Coviden 1lc; 2012. Available from: http://www.covidien.com/imageServer.aspx?contentID=35727\& contenttype=application/pdf. Accessed March 28, 2013.

30. Moog.com [homepage on the Internet]. Enteral feeding pumps. EnteraLite Infinity. Moog Inc.; 2014 [cited March 28, 2014]. Available from: http://www.moog.com/products/medical-pump-systems/enteralfeeding-pumps/enteralite-infinity/. Accessed May 24, 2014.

31. Freijer K, Bours MJ, Nuijten M, et al. The economic value of enteral medical nutrition in the management of disease-related malnutrition: a systematic review. J Am Med Dir Assoc. 2014;15(1):17-29.

32. Elia M, Stratton RJ. A cost-utility analysis in patients receiving enteral tube feeding at home and in nursing homes. Clin Nutr. 2008;27(3): 416-423.

33. Bristol S, Meer M, Bashar A, et al. Financial benefit of closed versus open enteral delivery system. Nutr Clin Pract. 2008;23(2):236-237.

34. Phillips W, Roman B, Glassman K. Economic impact of switching from an open to a closed enteral nutrition feeding system in an acute care setting. Nutr Clin Pract. 2013;28(4):510-514.

35. De Jonghe B, Appere-De-Vechi C, Fournier M, et al. A prospective survey of nutritional support practices in intensive care unit patients: what is prescribed? What is delivered? Crit Care Med. 2001;29(1):8-12.

36. Strack van Schijndel RJM, Weijs PJM, Koster C, Bissumbhar A, Melis GC, Girbes ARJ. A closer look at enterally delivered nutrition in the ICU; what you see is not what they get. e-SPEN Journal. 2007;2(1):1-3.

37. Kim H, Shin JA, Shin JY, Cho OM. Adequacy of nutritional support and reasons for underfeeding in neurosurgical intensive care unit patients. Asian Nursing Research. 2010;4(2):102-110.

38. Roberts SR, Kennerly DA, Keane D, George C. Nutrition support in the intensive care unit. Adequacy, timeliness, and outcomes. Crit Care Nurse. 2003;23(6):49-57.

39. Dietscher JE, Foulks CJ, Waits M. Accuracy of enteral pumps: in vitro performance. JPEN J Parenter Enteral Nutr. 1994;18(4):359-361.
40. Tepaske R, Binnekade JM, Goedhart PT, Schultz MJ, Vroom MB, Mathus-Vliegen EM. Clinically relevant differences in accuracy of enteral nutrition feeding pump systems. JPEN J Parenter Enteral Nutr. 2006;30(4):339-343.

41. Spronk PE, Rommes JH, Kuiper MA. Structural underfeeding due to inaccurate feeding pumps? JPEN J Parenter Enteral Nutr. 2007;31(2):154; author reply 155 .

42. Wallace JR, Payne RW, Mack AJ. Inadvertent intravenous infusion of milk. Lancet. 1972;229(7763):1264-1266.

43. Guenter P, Hicks RW, Simmons D, et al. Enteral feeding misconnections: a consortium position statement. Jt Comm J Qual Patient Saf. 2008;34(5):285-292, 245.

44. Nrls.npsa.nhs.uk [homepage on the Internet]. Promoting safer measurement and administration of liquid medicines via oral and other enteral routes [patient safety alert]. National Patient Safety Agency (UK); 2007 [cited March 28, 2014]. Available from: http://www.npsa.nhs.uk/nrls/ alerts-and-directives/alerts/liquid-medicines/. Accessed May 24, 2014.

45. Guenter P, Hicks RW, Simmons D. Enteral feeding misconnections: an update. Nutr Clin Pract. 2009;24(3):325-334.

46. Staebler S. Enteral feeding misconnections in the NICU: a continuing patient safety threat. Adv Neonatal Care. 2013;13(6):447-453.

47. Enteral Feeding Set Working Group of the AAMI Infusion Device Committee. Enteral feeding set adaptors and connectors. Arlington, VA: Association for the Advancement of Medical Instrumentation; 2000. Available from: http://marketplace.aami.org/eseries/scriptcontent/docs/ Preview\%20Files/ID54preview.pdf. Accessed June 27, 2014.

48. Pratt N. Tubing misconnections: a perilous design flaw. Mater Manag Health Care. 2006;15(11):36-39.

49. Guenter PA, Silkroski M. Tube Feeding: Practical Guidelines and Nursing Protocols. Gaithersburg, MD: Aspen Publishers, Inc.; 2001.

50. Fda.gov [homepage on the Internet]. Draft guidance for industry and Food and Drug Administration staff - safety considerations for 510(k) submissions to mitigate the risks of misconnections. Food and Drug Administration; 2012 [updated March 18, 2014; cited March 28, 2014]. Available from: http://www.fda.gov/MedicalDevices/DeviceRegulationandGuidance/ GuidanceDocuments/ucm313382.htm. Accessed May 24, 2014.

51. Macleod JB, Lefton J, Houghton D, et al. Prospective randomized control trial of intermittent versus continuous gastric feeds for critically ill trauma patients. $J$ Trauma. 2007;63(1):57-61.

52. Ciocon JO, Galindo-Ciocon DJ, Tiessen C, Galindo D. Continuous compared with intermittent tube feeding in the elderly. JPEN J Parenter Enteral Nutr. 1992;16(6):525-528.

53. Shang E, Geiger N, Sturm JW, Post S. Pump-assisted enteral nutrition can prevent aspiration in bedridden percutaneous endoscopic gastrostomy patients. JPEN J Parenter Enteral Nutr. 2004;28(3):180-183.

54. Lee JS, Kwok T, Chui PY, et al. Can continuous pump feeding reduce the incidence of pneumonia in nasogastric tube-fed patients? A randomized controlled trial. Clin Nutr. 2010;29(4):453-458.

55. Kirby DF, Delegge MH, Fleming CR. American Gastroenterological Association technical review of tube feeding for enteral nutrition. Gastroenterology. 1995;108(4):1282-1301.

56. Niv E, Fireman Z, Vaisman N. Post-pyloric feeding. World J Gastroenterol. 2009;15(11):1281-1288.

57. Center for Devices and Radiological Health. Safety Assessment of Di(2-ethylhexyl)phthalate (DEHP) Released from PVC Medical Devices. Rockville, MD: Food and Drug Administration; 2001. Available from: http:// www.fda.gov/downloads/medicaldevices/deviceregulationandguidance/ guidancedocuments/ucm080457.pdf. Accessed March 28, 2014.

58. Schettler T. DEHP Exposures during the Medical Care of Infants: A Cause for Concern. Arlington, VA: Health Care Without Harm; 2002. Available from: http://noharm.org/lib/downloads/pvc/DEHP_ Exposure_of_Infants.pdf. Accessed May 24, 2014.

59. Health Care Without Harm. The Weight of the Evidence on DEHP, Exposures are a Cause of Concern Especially during Medical Care. Arlington, VA: Health Care Without Harm; 2009. Available from: http://noharm.org/lib/downloads/pvc/Weight_of_Evidence_DEHP.pdf. Accessed March 25, 2014. 
60. Liley AJ, Manthorpe J. The impact of home enteral tube feeding in everyday life: a qualitative study. Health Soc Care Community. 2003;11(5):415-422.

61. Bjuresäter K, Larsson M, Athlin E. Struggling in an inescapable life situation: being a close relative of a person dependent on home enteral tube feeding. J Clin Nurs. 2012;21(7-8):1051-1059.

62. Brotherton A, Abbot J, Hurley M, Aggett PJ. Home enteral tube feeding in children following percutaneous endoscopic gastrostomy: perceptions of parents, paediatric dietitians and paediatric nurses. J Hum Nutr Diet. 2007;20(5):431-439.

63. Evans S, MacDonald A, Holden C. Home enteral feeding audit. J Hum Nutr Diet. 2004;17(6):537-542.

64. Evans S, MacDonald A, Daly A, Hopkins V, Holden C. Home enteral tube feeding in patients with inherited metabolic disorders: safety issues. J Hum Nutr Diet. 2007;20(5):440-445.

65. Daley T. Tube-Fed Patients May Be Suffering Due to Lack of Physical Activity. Salt Lake City, UT: Zevex Inc.; 2005. Available from: http://www.moog.com/literature/Medical/Enteral/Clinical_Studies/ Whitepaper_on_Physical_Activity.pdf. Accessed May 24, 2014.
66. Best C. Supporting home enteral tube feeding: some considerations. Br J Community Nurs. 2012;17(Suppl 7):S6-S10.

67. British Artificial Nutrition Society (BANS). Annual BANS Report, 2011, Artificial Nutrition Support in the UK, 2009-2010. Redditch: British Association for Parenteral and Enteral Nutrition; 2011. Available from: http://www.bapen.org.uk/pdfs/bans_reports/bans_report_11.pdf. 2011. Accessed March 24, 2014.

68. psychmamma.wordpress.com [homepage on the Internet]. Special needs Sunday: enteral feeding pump. PsychMamma; 2008 [cited March 24, 2014]. Available from: http://psychmamma.wordpress.com/2008/06/29/ special-needs-sunday-enteral-feeding-pump/. Accessed March 24, 2014.

69. mumsnet.com [homepage on the Internet]. Mumsnet talk. New Abbott Freego feeding pump. Mumsnet; 2011 [cited March 24, 2014]. Available from: http://www.mumsnet.com/Talk/special_needs/a1322276-NewAbbott-FreeGo-Feeding-Pump-problems. Accessed May 24, 2014.

\section{Publish your work in this journal}

Medical Devices: Evidence and Research is an international, peerreviewed, open access journal that focuses on the evidence, technology, research, and expert opinion supporting the use and application of medical devices in the diagnosis, treatment and management of clinical conditions and physiological processes. The identification of novel devices and optimal use of existing devices which will lead to improved clinical outcomes and more effective patient management and safety is a key feature. The manuscript management system is completely online and includes a quick and fair peer-review system. Visit http://www. dovepress.com/testimonials.php to read real quotes from authors. 